\title{
Estrutura da regeneração natural de Anadenanthera colubrina em fragmento de brejo de altitude em Bananeiras, PB
}

\author{
Robson Luis Silva de Medeiros ${ }^{1 *}$, Vênia Camelo de Souza², Miguel Avelino Barbosa Neto², Leandro de Araújo², Alex da Silva Barbosa², \\ Rafael Luis Silva de Medeiros $^{2}$
}

1 Universidade Estadual Paulista Júlio Mesquita Filho, Via de acesso Prof. Paulo Donato Castellane, km 5 rural, CEP 14884-900, Jaboticabal, SP, Brasil ${ }^{2}$ Universidade Federal da Paraíba, Campus III, CEP 58220-000, Bananeiras, PB, Brasil

*Autor correspondente:

robsonluissm@hotmail.com

Termos para indexação:

Fatores abióticos

Recrutamento

Mortalidade

Index terms:

Abiotic factors

Recruitment

Mortality

Histórico do artigo:

Recebido em 19/03/2015

Aprovado em 04/04/2016

Publicado em 30/06/2016

doi: $10.4336 / 2016 . p f b .36 .86 .887$

Resumo - A destruição de habitats atrelada à fragmentação causa sérias consequências para qualquer tipo de vegetação, principalmente para a Mata Atlântica na Região Nordeste. Os Brejos de Altitudes Nordestinos são áreas que apresentam microclimas dissociantes das extensões onde estão inseridos. O conhecimento do potencial de regeneração natural é fundamental para a compreensão da dinâmica da vegetação. Este trabalho teve como objetivo avaliar a o recrutamento e a mortalidade de regenerantes de Anadenanthera colubrina ocorrente em fragmento florestal de Floresta Ombrófila Aberta. Em uma população de A. colubrina as parcelas foram demarcadas, onde existiam plantas matrizes, com plântulas regenerantes, sendo 10 parcelas fixas (10 m x $10 \mathrm{~m})$, onde todos os exemplares dessa espécie menor ou igual a $1 \mathrm{~m}$ de altura foram marcados, numerados e acompanhados durante 9 meses. $\mathrm{O}$ diâmetro caulinar do táxon apresentou crescimento constante. O incremento médio mensal inicial em diâmetro foi de $1,8 \mathrm{~mm}$ e final de $2,3 \mathrm{~mm}$ e o incremento médio em altura foi de $20 \mathrm{~cm}$ no primeiro mês e $25,9 \mathrm{~cm}$ no último mês avaliado. A taxa de mortalidade chegou a $50 \%$. Os fatores ambientais e antrópicos e a predação das sementes contribuem para a mortalidade dos regenerantes.

\section{Structure of natural regeneration in Anadenanthera colubrina altitude swamp fragment in Bananeiras, PB, Brazil}

\begin{abstract}
The habitats destruction linked to fragmentation causes serious consequences for vegetation in general, especially considering the Northeast Atlantic Forest. The Northeastern Swamps of Altitudes are areas with microclimates dissociating from extensions where they are inserted. Knowledge of the natural regeneration potential is the key to understanding the dynamics of vegetation. The study aimed to evaluate the recruitment and mortality of Anadenanthera colubrina regenerating occurring in Open Rain Forest fragments. In a population of A. colubrina, ten plots with $10 \mathrm{~m} \mathrm{x}$ $10 \mathrm{~m}$ were established, near matrices plants. All specimens with $1 \mathrm{~m}$ height or lower were numbered and monitored for 9 months. The stem diameter of the taxon showed continuous growth. The monthly average increment in diameter was at first $1.8 \mathrm{~mm}$ and at the end $2.3 \mathrm{~mm}$, and the average stem increment in height was $20 \mathrm{~cm}$ at the first month and $25.9 \mathrm{~cm}$ at the last month evaluate. The mortality rate reached $50 \%$. Environmental and anthropogenic factors and seed predation contribute to mortality of regenerating individuals.
\end{abstract}

\section{Introdução}

A floresta tropical, por ser um ecossistema complexo, apresenta um desafio para a ciência florestal, sendo importante conhecer seus recursos e necessidades
(Marangon et al., 2008). A destruição de habitats atrelada à fragmentação causa sérias consequências para qualquer tipo de vegetação, principalmente para a Mata Atlântica na Região Nordeste que se encontra extremamente fragmentada, onde se podem destacar os brejos de 
altitude e ecossistemas associados no Estado da Paraíba. Possivelmente, espécies que ocorrem nesses fragmentos estão tendo algum tipo de impacto, necessitando de estudos que relacionem dados de estrutura populacional e dinâmica, imprescindíveis para indicar espécies que necessitam de ações conservacionistas.

$\mathrm{O}$ conhecimento da biodiversidade de uma região constitui um pré-requisito básico para o manejo e a gestão do seu patrimônio genético. Principalmente no que se refere às espécies vegetais, é fundamental conhecer as preferências das mesmas por determinados sítios ou condições biofísicas que possam determinar a abundância de suas populações ou mesmo a distribuição geográfica desses táxons (Andrade et al., 2008).

Os Brejos de Altitudes Nordestinos são áreas que apresentam microclimas dissociantes das extensões onde estão inseridos (semiárido). Este fator está associado ao efeito orográfico, planaltos e chapadas entre $600 \mathrm{~m}$ e $1.100 \mathrm{~m}$ de altitude, que aumentam os níveis de pluviosidade e diminuem as temperaturas, onde formam "ilhas" de microclima diferenciado. Suas formações florestais são disjunções de Floresta Atlântica, ilhadas pela vegetação da Caatinga, com condição que tornam esses remanescentes áreas de elevada biodiversidade (Barbosa et al., 2004). Segundo Veloso et al. (1991) afirmam que esta tipologia pode ser considerada como relíquia vegetacional, por proporcionar peculiaridades florísticas, fisionômicas e ecológicas dissonantes do contexto em que está inserido.

Por apresentar condições climáticas bastante favoráveis à agricultura, os brejos de altitude têm sido considerados áreas prioritárias de ocupação e desenvolvimento de atividades de pecuaristas e agricultores.

De acordo com a Sociedade Nordestina de Ecologia (2002), a Paraíba possuía originalmente $12 \%$ de seu território coberto por formações florestais desta tipologia, tendo sua área drasticamente reduzida, a somente 1,2\% desta vegetação. Silva \& Tabarelli (2000) afirmam que restam apenas $949 \mathrm{~km}^{2}$ de floresta nos brejos da Paraíba e Pernambuco, grande parte representada pela Floresta Estacional Semidecidual e apenas $25 \mathrm{~km}^{2}$ de Floresta Ombrófila Aberta nos brejos. Além disso, as florestas nos brejos estão extremamente fragmentadas.

O conhecimento do potencial de regeneração natural é fundamental para a compreensão da dinâmica da vegetação, possibilitando a elaboração de planos de manejo de florestas naturais de modo sustentável e a elaboração de caminhos para a aplicação de práticas de restauração (Valeri et al., 2003). As espécies da floresta tropical se regeneram através de diversos mecanismos, como o banco de sementes do solo, chuva de sementes, banco de plântula e brotações. Essas diferentes estratégias garantem a renovação, sustentabilidade e manutenção da diversidade biológica destes ecossistemas (Almeida, 2000).

Segundo Santos et al. (2013), o angico (Anadenanthera colubrina) é uma das espécies de maior importância em fragmentos de floresta nos brejos da Paraíba. Trata-se de uma árvore de porte arbóreo, perenifólia a semicaducifólia, podendo atingir 20 a $35 \mathrm{~m}$ de altura. Esta espécie é exigente em luz, possuindo frequência populacional nas Florestas Estacionais, Semideciduais e Deciduais, no domínio da Caatinga, Mata Atlântica, Cerrado, Pantanal e Campos Rupestres ou de Altitude (Berg \& Silva, 1986). É uma espécie heliófila, originária da sucessão secundária inicial. Utilizada em arborização de pastos, também é empregada na confecção de tacos, ripas, embalagens, lenha e carvão de boa qualidade (Carvalho, 1994).

Segundo Durigan (1991), as espécies do gênero Anadenanthera são procedentes das formações de mata ciliar e cerradões, o que lhes confere um papel fundamental na manutenção dessas unidades fitogeográficas.

Diante do exposto, o objetivo deste trabalho foi avaliar a estrutura, recrutamento e mortalidade de $A$. colubrina em fragmento de Floresta Ombrófila no Município de Bananeiras, PB.

\section{Material e métodos}

A pesquisa foi desenvolvida em um remanescente de Floresta Ombrófila Aberta, pertencente a Reserva Florestal da Universidade Federal da Paraíba-CCHSA/ UFPB. É considerado um importante fragmento florestal ecotonal de Brejo de Altitude. Está situado na microrregião de Brejo Paraibano, na Cidade de Bananeiras, PB e possui aproximadamente 35,5 ha, cujas coordenadas são: $6^{\circ} 46^{\prime} \mathrm{S}$ e $35^{\circ} 38^{\prime} \mathrm{W}$, com altitude entre $510 \mathrm{~m}$ e $617 \mathrm{~m}$. O clima da região é As' (tropical chuvoso) quente e úmido (Classificação de Köppen) e se caracteriza por apresentar temperatura máxima de $38{ }^{\circ} \mathrm{C}$ e mínima de $18{ }^{\circ} \mathrm{C}$, com chuvas de outono a inverno (concentradas nos meses de maio a agosto) (Santos et al., 2013). 
O solo da reserva é do tipo Latossolo Amarelo Distrófico, textura franco arenosa a franco argilosa, fase floresta tropical subperenifólia. Geomorfologicamente, caracteriza-se pelo relevo suave ondulado (Sistema..., 1999).

Os dados de estrutura foram coletados em novembro de 2013 e foi realizado um acompanhamento dos regenerantes no período de novembro de 2013 a julho de 2014.

\section{Amostragem da população}

Foi selecionada uma população de A. colubrina, sendo as parcelas alocadas onde existiam planta matrizes, com plântulas regenerantes. Foram plantadas 10 parcelas fixas $(10 \mathrm{~m}$ x $10 \mathrm{~m})$, totalizando uma área amostral de $1.000 \mathrm{~m}^{2}$. No levantamento foi utilizado o método das parcelas (Muller-Dombois \& Ellemberg, 1974), sendo que todos os indivíduos regenerantes de $A$. colubrina menor ou igual a $1 \mathrm{~m}$ de altura foram contados, marcados e acompanhados. O número designado para os indivíduos foi sequencial e correspondeu ao momento de seu aparecimento no censo. Mensalmente, as parcelas foram monitoradas para contagem de novos ingressos e registro de mortalidade.

\section{Análise dos dados}

Para a variável altura $(\mathrm{cm})$, utilizou-se réguas de $30 \mathrm{~cm}$ e $1 \mathrm{~m}$, para diâmetro do colo $(\mathrm{mm})$, foi utilizado paquímetro digital com precisão de $0,01 \mathrm{~mm}$. Para as variáveis altura e diâmetro, foi realizada, one-way (Anova de um critério), utilizando-se o software SAS 9.2 (Statistical Analysis System Institute, 2009). Foi calculada a taxa de mortalidade utilizando-se as médias mensais dos indivíduos mortos pelo total de parcelas.

Os dados de estrutura populacional obtidos em novembro de 2013 foram: densidade absoluta (DA), área basal (AB), frequência absoluta (FA), densidade relativa (DR), dominância relativa (DoR), frequência relativa (FR) e valor de importância (VI) (Kent \& Coker, 1992), utilizado-se o software Mata Nativa (Cientec, 2001). Para a análise de agregação de indivíduos da mesma espécie, fez-se uso do índice de McGuinnes (IGA) ou índice de agregação, através da fórmula IGA $=\mathrm{D} / \mathrm{d}$, onde: $\mathrm{D}=$ número total de indivíduos da espécie pelo número total de parcelas alocadas, enquanto que $\mathrm{d}=-\ln (1-\mathrm{FA} / 100)$. McGuinnes (IGA) - IGAi $<1$ é distribuição uniforme, $\mathrm{IGAi}=1$ é distribuição aleatória, $1<\mathrm{IGAi} \leq 2$ é tendência ao agrupamento, IGAi $>2$ é distribuição agregada ou agrupada (Cientec, 2006).

\section{Resultados e discussão}

\section{População de Anadenanthera colubrina}

No estrato regenerante, foi levantado um total de 1.193 indivíduos em novembro de 2013. Este estrato populacional equivale a 11.930 ind $\mathrm{ha}^{-1}$. A maior parte dos indivíduos em fase de plântulas se encontrava próximo aos indivíduos adultos.

Santos et al. (2013) estudaram a fitossociologia no mesmo fragmento florestal e amostraram 179 indivíduos regenerantes de $A$. colubrina, em cinco unidades amostrais de um total de vinte e duas (22), com um valor de importância relativo (VI) do táxon de 5,86\% enquanto Santiago et al. (2014) encontraram VI de $7,5 \%$, trabalhando com fitossociologia da regeneração natural de um fragmento urbano de Floresta Estacional Semidecidual em Juiz de Fora, MG. Entretanto, para a área basal $(\mathrm{AB})$ de $A$. colubrina neste tipo de fitocenose, Santos et al. (2013) encontraram 0,9922 $\mathrm{m}^{2}$, que difere dos dados encontrados no presente trabalho $\left(0,456 \mathrm{~m}^{2}\right)$. A densidade de indivíduos dessa espécie para este estrato resultou em 406,818 ind ha $^{-1}$, muito inferior ao observado neste trabalho (9.880 ind ha-1). Oliveira et al. (2006) quando trabalharam com fragmentos jovens de Floresta Ombrófila no Município de Areia, $\mathrm{PB}$, encontraram uma densidade de 52 ind $\mathrm{ha}^{-1}$ de $A$. colubrina, indicando o pioneirismo da espécie também neste tipo de fitofisionomia. Vale a ressalva que as diferenças encontradas em alguns dados podem ser explicadas em virtude da diferente intensidade amostral entre trabalhos, e pelas características e peculiaridades fisionômicas de cada local de estudo.

Em um levantamento florístico e fitossociológico, que amostrou indivíduos juvenis e adultos, realizado por Santos et al. (2013), foi evidenciado que $A$. colubrina apresentou forma agregada $(\mathrm{IGA}=31,56)$, no estrato regenerante, semelhante ao observado no presente estudo $(\mathrm{IGA}=8,58)$.

Observa-se na Figura 1 a relação entre a estrutura diamétrica do angico (A. colubrina) e o número de indivíduos amostrados. Nota-se que a maior parte da população dos regenerantes $(89,5 \%)$ apresenta diâmetro do colo menor do que $5,0 \mathrm{~mm}$. A mesma tendência foi registrada em trabalho realizado por Santos et al. (2013), no mesmo fragmento estudado.

A população apresenta ampla dispersão na área, embora haja um número relativamente menor de indivíduos do estrato adulto, quando correlacionado com 
o estrato regenerante, sendo este fato bastante comum em formações florestais jovens. Embora Santos et al. (2013), tenham trabalhado em comunidade vegetal com florística e fitossociologia no mesmo fragmento, os autores constataram que Anadenanthera colubrina foi a terceira espécie com maior valor de importância (VI), apresentando 4,773 ind ha ${ }^{-1}$, frequência de $27,27 \%$ e dominância de $13,04 \mathrm{~m}^{2} \mathrm{ha}^{-1}$, gerando um valor de cobertura de 15,43 e valor de importância de 17,6\%, correspondendo a $4,5 \%$ da amostra total de plantas levantadas.

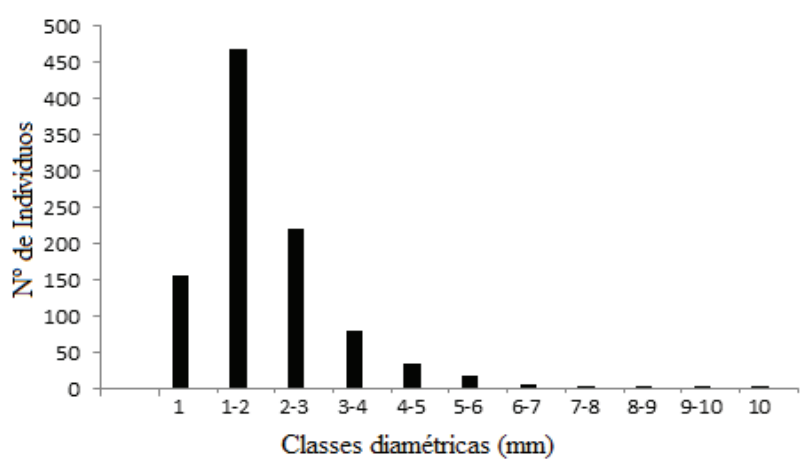

Figura 1. Estrutura diamétrica populacional (estrato regenerante) de A. colubrina, em remanescente de Floresta Ombrófila Aberta, Bananeiras, PB, 2013.

Na Figura 2 é apresentada a relação entre a estrutura hipsométrica do angico (A. colubrina) e o número de indivíduos amostrados em remanescente da Floresta Ombrófila Aberta, em Bananeiras, PB.

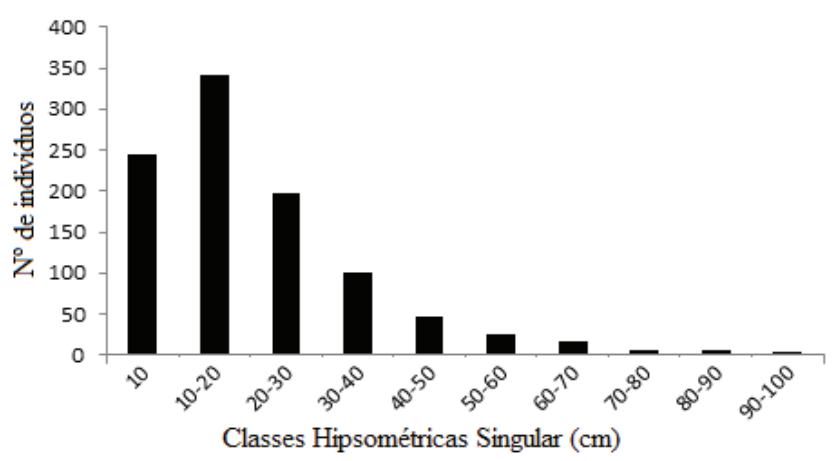

Figura 2. Estrutura hipsométrica populacional (estrato regenerante) de A. colubrina, em remanescente de Floresta Ombrófila Aberta, Bananeiras, PB, 2013.

Tendo em vista as peculiaridades da floresta, observase que a população está bem estabelecida e que se perpetuará no futuro, caso não haja perturbação no ambiente. Onde, 79,4\% representam as 3 primeiras classes, sendo, $24,6 \%$ até $10 \mathrm{~cm}, 34,6 \%$ entre $>10-20 \mathrm{~cm}$ e $20 \%>20-30 \mathrm{~cm}$.

\section{Regeneração}

A. colubrina apresenta abundância de indivíduos regenerantes na população, com distribuição espacial de forma agregada.

De modo geral, o principal fator que designou a forma de distribuição agregada na fase regenerante, é a forma de dispersão barocórica (pela ação da gravidade). Segundo Arruda \& Daniel (2007), através do índice de agregação é possível visualizar a distribuição espacial das espécies dentro da comunidade, característica imprescindível para o planejamento de medidas de manejo e conservação de formações florestais.

O comportamento dispersivo (barocórica) contribui para garantir um grande contingente de sementes na serrapilheira, garantindo um fornecimento e apoio básico ao estoque de plântulas embaixo das copas dos indivíduos adultos. Outro fator que atua fortemente na quantidade de indivíduos em fase de plântula é que as sementes deste táxon apresentam-se vigorosas ao final do estádio de amadurecimento e não apresentam dormência tegumentar ou embrionária (Lorenzi, 2002).

$\mathrm{Na}$ área estudada, a presença de matéria orgânica, luminosidade, umidade e temperatura são condições satisfatórias para as sementes permanecerem e posteriormente germinarem, com o aumento do número de plântulas. Essas condições contribuem para a perpetuação da espécie na área bem como favorecem a manutenção das relações ecológicas (Santos et al., 2013).

NaFigura 3 estão apresentados os dados pluviométricos mensais durante a coleta de dados dos indivíduos regenerantes de angico. Verifica-se que os meses com maior índice de pluviosidade foram março, maio e junho de 2014, durante o inverno, enquanto que os meses com menor pluviosidade foram novembro e dezembro de 2013 e abril de 2014.

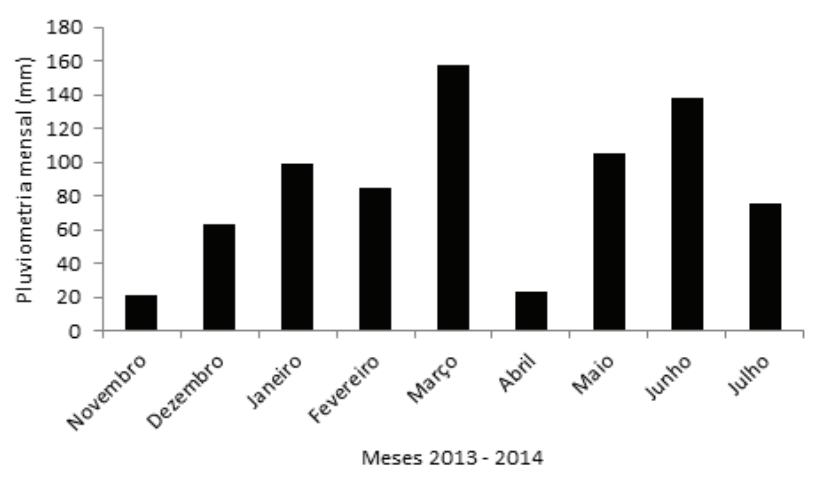

Figura 3. Pluviometria mensal (mm) do Município de Solânea, PB, nos anos de $2013-2014$. 
Os dados de média de diâmetro do colo dos indivíduos regenerantes de angico se ajustaram ao modelo de regressão linear (Figura 4). No mês 1 (novembro de 2013), foram marcados 1.193 indivíduos da espécie. $\mathrm{O}$ diâmetro caulinar do táxon apresentou crescimento constante. No início, a média mensal foi de $1,8 \mathrm{~mm}$ e ao final de 2,3 $\mathrm{mm}$ (Figura 4), apresentando 0,5 (cm) de crescimento durante o período estudado. A redução do diâmetro no mês 8 , foi devido a número elevado de indivíduos ingressantes em junho e julho.

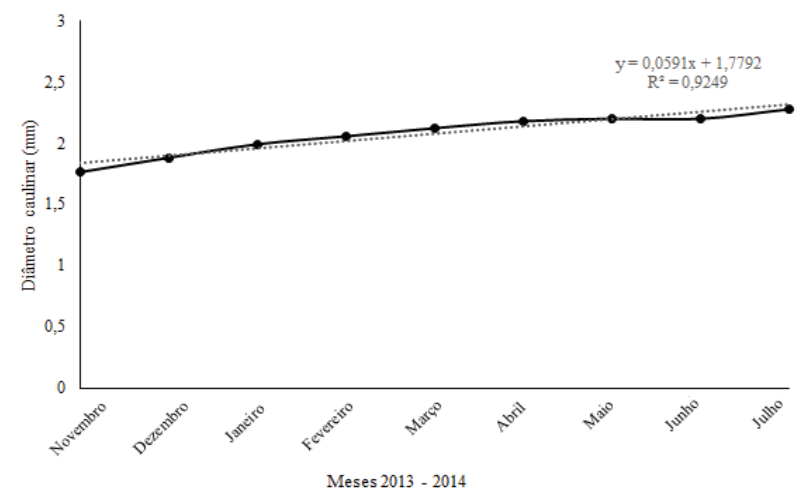

Figura 4. Média de diâmetro caulinar de indivíduos regenerantes de Anadenanthera colubrina em fragmento de Floresta Ombrófila Aberta, Bananeiras, PB.

Os dados da média de altura dos indivíduos regenerantes de angico se ajustaram ao modelo de regressão linear (Figura 5). As plantas apresentaram médias da altura caulinar de $20 \mathrm{~cm}$ no mês 1 e $25,9 \mathrm{~cm}$ ao final das avaliações. Semelhante ao observado para os diâmetros, os valores médios de altura foram inferiores nas avaliações feitas em junho e julho, devido ao elevado número de ingressantes.

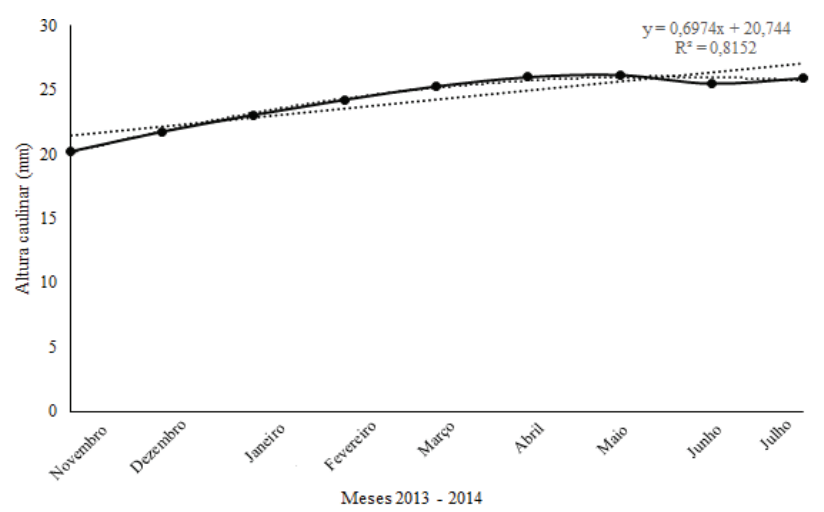

Figura 5. Média da altura caulinar $(\mathrm{cm})$ de indivíduos regenerantes de Angico em fragmento de Floresta Ombrófila Aberta, Bananeiras, PB.
A taxa de mortalidade foi crescente no período estudado (figura 6), atingindo $42,5 \%$ em maio e quase $50 \%$ em julho de 2014, diminuindo a média mensal de crescimento.

De acordo com Still (1996), a mortalidade mais intensa em plantas ocorre no estágio juvenil. Na ausência de distúrbios em larga escala, a dinâmica da regeneração é fortemente influenciada por fatores endógenos (estruturas da vegetação e interação entre espécies). Paludo et al. (2011) afirma que a fase crítica de desenvolvimento da regeneração de Araucaria angustifolia é até $50 \mathrm{~cm}$ de altura, e a mortalidade estende-se até a classe de $2 \mathrm{~m}$ de altura, semelhante ao observado neste trabalho com angico, onde foi observada taxa de $50 \%$ de mortalidade com táxon até $1 \mathrm{~m}$ de altura. Almeida (2000), afirma que a regeneração natural é muito afetada por fatores abióticos e a disponibilidade destes, competição, presença de predadores, microorganismos do solo, como micorrizas e fungos. A combinação desses e outros fatores irão determinar quais espécies sobreviverão e ocuparão o dossel superior do ecossistema florestal. $\mathrm{O}$ mesmo autor ressalta ainda que no período entre a germinação das sementes e o estabelecimento das plântulas existe um intenso processo de herbivoria, limitando a densidade populacional das espécies que vão compor o banco de plântulas.

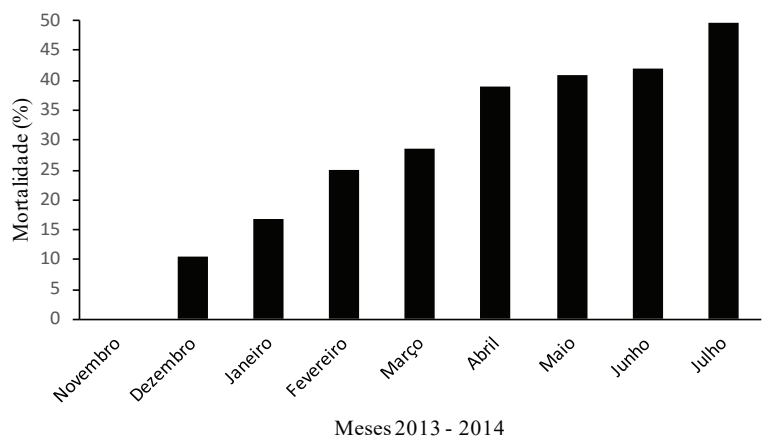

Figura 6. Porcentagem da mortalidade de indivíduos regenerantes de Angico em fragmento de Floresta Ombrófila Aberta, Bananeiras, PB.

Pode-se observar na Figura 7 o índice de sobreviventes em novembro/2013 até julho/2014, com redução a cada mês. Na última leitura realizada em julho/2014, apenas $31,7 \%$ havia sobrevivido, ou seja, quase $70 \%$ dos regenerantes morreram em apenas 10 meses. Esse fator pode ser explicado por chuvas frequentes no fragmento estudado, declividade, biomassa que fica sobre os indivíduos regenerantes, dificultando seu crescimento, 
entre outros. A sobrevivência e desenvolvimento dos indivíduos da regeneração dependem de fatores fenológicos, genéticos e ambientais (Felfili \& Rezende, 2003).

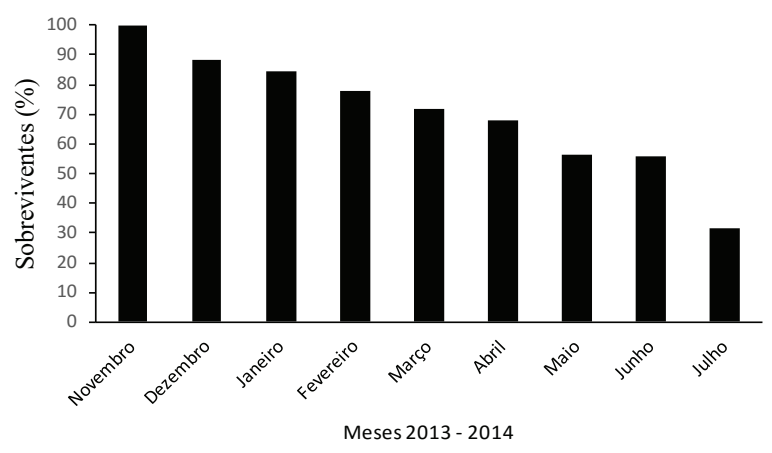

Figura 7. Taxa de sobrevivência de indivíduos regenerantes de Angico em fragmento de Floresta Ombrófila Aberta, Bananeiras, PB.

A grande parte dos indivíduos mortos são plântulas, por sua fragilidade e pouca adaptabilidade, como foi observado nas parcelas durante o estudo. O angicobranco foi enquadrado por Ferretti et al. (1995) numa transição entre secundária inicial e tardia. As espécies secundárias, também denominadas oportunistas, geralmente produzem sementes que apresentam poucas restrições com relação aos fatores que afetam a germinação (Piña-Rodrigues et al., 1990; Kageyama \& Viana, 1991), devendo germinar de forma similar tanto em clareiras quanto sob o dossel. O processo de dispersão por si só, no entanto, não garante o sucesso da regeneração, mas é preciso que condições de solo, clima e a relação com os predadores sejam apropriadas para o estabelecimento das plantas jovens (Mcclanahan \& Wolfe, 1993).

\section{Conclusões}

A espécie Anadenanthera colubrina apresenta abundância de indivíduos regenerantes no ecossistema avaliado, apesar de ter-se constatado alta mortalidade.

A intensidade e frequência das chuvas no fragmento estudado, além da declividade e biomassa vegetal que fica sobre os indivíduos regenerantes, fatores antrópicos e predação de sementes, provavelmente, contribuem para o aumento da mortalidade dos indivíduos regenerantes.

É necessário acompanhamento da dinâmica de regeneração natural do angico no fragmento estudado por mais tempo, para obtenção de resultados mais consistentes.

\section{Agradecimentos}

Ao Centro de Ciências Humanas, Sociais e Agrárias de Bananeiras, PB, a PRPG/UFPB e o CNPq, pelo fomento da pesquisa.

\section{Referências}

Almeida, D. S. Recuperação ambiental da mata atlântica. Ilhéus: Editus, 2000. 130 p.

Andrade, L. A. et al. Algaroba (Prosopis juliflora (Sw.) DC.): impactos sobre a fitodiversidade e estratégias de colonização em área invadida na Paraíba, Brasil. Natureza e Conservação, v. 6, n. 2, p. 61-67, 2008. DOI: 10.4025/actascibiolsci.v32i3.4535.

Arruda, L. \& Daniel, O. Florística e diversidade em um fragmento de floresta estacional semidecidual aluvial em Dourados-MS. Floresta, v. 37 , n. 2 , p. $189-199,2007$. DOI: 10.5380/rf.v37i2.8649.

Barbosa, M. R. V. et al. Diversidade florística na Mata do Pau-Ferro, Areia, Paraíba. In: Pôrto, K. C. et al. (Org.). Brejos de altitude em Pernambuco e Paraíba: história natural, ecologia e conservação. Brasília, DF: Ministério do Meio Ambiente, 2004. p. 111-122.

Berg, M. E. V. D. \& Silva, M. H. L. da. Contribuição ao conhecimento da flora medicinal do Maranhão. In: SIMPÓSIO DO TRÓPICO ÚMIDO, 1., 1984, Belém, PA. Flora e floresta: anais. Brasília, DF: Embrapa-CPATU, 1986. v. 2. p. 119-125.

Carvalho, N. M. O conceito de vigor em sementes. In: Vieira, R. D.; Carvalho, N. M. (Ed.). Teste de vigor em sementes. Jaboticabal: FUNEP, 1994. p. 1-30.

Cientec. Software mata nativa: manual do usuário. Viçosa, MG, 2001. $131 \mathrm{p}$.

Durigan, G. Análise comparativa do modo de dispersão das sementes das espécies de cerradão e de mata ciliar, no município de Assis, SP. In: SIMPÓSIO BRASILEIRO SOBRE TECNOLOGIA DE SEMENTES FLORESTAIS, 2., 1989, Atibaia. Anais... São Paulo: Instituto Florestal/Secretaria do Meio Ambiente, 1991. p. 278.

Felfili, J. M. \& Rezende, R. P. Conceitos e métodos em fitossociologia. Brasília, DF: Universidade de Brasília, 2003. 68 p. (Comunicações técnicas florestais, v. 5, n.1 ).

Ferretti, A. R. et al. Classificação das espécies arbóreas em grupos ecológicos para revegetação com nativas no Estado de São Paulo. Florestar Estatístico, v. 3, n. 7, p. 73-77, 1995.

Kageyama, P. Y. \& Viana, V. M. Tecnologia de sementes e grupos ecológicos de espécies arbóreas tropicais. In: SIMPÓSIO BRASILEIRO SOBRE TECNOLOGIA DE SEMENTES FLORESTAIS, 2., 1989, Atibaia. Anais. São Paulo: UNIPRESS, 1991. p. 197-215.

Kent, M. \& Coker, P. Vegetation description and analysis: apractical approach. New York: John Wiley \& Sons, 1992. 365 p.

Lorenzi, H. Árvores brasileiras: manual de identificação e cultivo de plantas arbóreas nativas do Brasil. 4. ed. Nova Odessa: Plantarum, 2002. 384 p. 
Marangon, L. C. et al. Regeneração natural em um fragmento de floresta estacional semidecidual em Viçosa, Minas Gerais. Revista Árvore, v. 32, n. 1, p. 183-191, 2008. DOI: 10.1590/S010067622008000100020 .

Mcclanahan, T. R. \& Wolfe, R. W. Accelerating forest succession in fragmented landscape: the role of brids and perches. Conservation Biology, v. 7, n. 2, p. 279-288, 1993.

Muller-Dombois, D. \& Ellemberg, H. Aims and methods of vegetation ecology. New York: John Wiley \& Sons, 1974. 547 p.

Oliveira, F. X. et al. Comparações florísticas e estruturais entre comunidades de Floresta Ombrófila Aberta com diferentes idades, no Município de Areia, PB, Brasil. Acta Botanica Brasilica, 2006, v. 20, n. 4, p. 861-873, 2006. DOI: 10.1590/S0102-33062006000400011.

Paludo, G. F. et al. Regeneração de uma população natural de Araucaria Angustifólia (Araucariaceae). Revista Árvore, v. 35, n. 5, p. 1107-1119, 2011. DOI: 10.1590/S0100-67622011000600017.

Piña-Rodrigues, F. C. M. et al. Estratégias de estabelecimento de espécies arbóreas e manejo de florestas tropicais. In: CONGRESSO FLORESTAL BRASILEIRO, 6., 1990, Campos do Jordão. Anais... São Paulo: SBS:SBEF, 1990. p. 676-684.

Santiago, D. S. et al. Fitossociologia da regeneração natural de um fragmento urbano de Floresta Estacional Semidecidual (Juiz de Fora, MG). Revista Brasileira de Ciências Agrárias, v. 9, n. 1, p. 117-123, 2014. DOI:10.5039/agraria.v9i1a3538.

Santos, J. N. B. et al. Estrutura populacional e análise da regeneração natural de Anadenanthera colubrina (vell.) brenan em um remanescente de floresta ombrófila densa, em Bananeiras-Pb. In: Seabra, G. (Org.). Terra: qualidade de vida, mobilidade e segurança nas cidades. João Pessoa: Ed. da UFPB, 2013. v. 3. p. 470-483.
Silva, J. M. C. \& Tabarelli, M. Tree species impoverishment and the future flora of the Atlantic Forest of northeast Brazil. Nature, v. 404, p. 72-74, 2000. DOI: 10.1038/35003563.

Sistema Brasileiro de Classificação de Solos. Brasília, DF: Embrapa Produção de Informação; Rio de Janeiro: Embrapa Solos, 1999. $412 \mathrm{p}$.

Still, M. J. Rates of mortality and growth in three groups of dipterocarp seedlings in Sabah, Malaysia. In: The Ecology of Tropical Forest seedlings. Paris: Parthenon Publishing Group, 1996. p. 315-331.

Sociedade Nordestina de Ecologia. Mapeamento da Mata Atlântica, seus ecossistemas associados dos estados da Paraíba e do Rio Grande do Norte: relatório técnico. São Paulo, 2002. Disponível em: $<$ https://www.sosma.org.br/tag/sociedade-nordestina-de-ecologia/ $>$. Acesso em: 13 jan. 2015.

Statistical Analisys System Institute. SAS Institute versão 9.2. Cary, 2009.

Valeri, S. V. et al. Manejo e recuperação florestal, legislação, uso da água e sistemas agroflorestais. Jaboticabal: FUNEP, 2003. 180 p.

Veloso, H. P. et al. Classificação da vegetação brasileira, adaptada a um sistema universal. Rio de Janeiro: IBGE, 1991. 91 p. 
